\title{
Preface
}

\section{Fulfilling a Need}

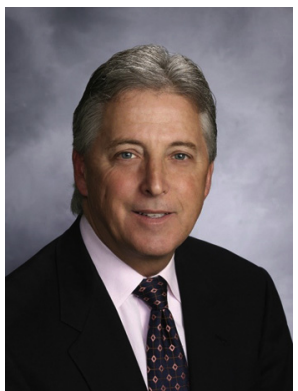

Edward D. Verrier, MD

Editor

We believe that resident surgical education in 2019 is being challenged both in and outside the operating room. Optimal outcomes are essential. Safety must be emphasized. Efficiency is paramount. Residents have duty-hour restrictions, and there is simply a malalignment of incentives distracting faculty. Expertise is not transferable across domains, and because one is an excellent academic or clinical surgeon does not mean they are excellent surgical educators without training. The responsibility to educate and train the next generation of surgeons is an essential responsibility to society. Surgical volume and complexity are increasing at a time when historically, the simpler cases, which for many years formed the basis of surgical training, are no longer done by surgeons. How do we not only maintain the historical excellence in surgical training we have come to know but actually improve? How do we implement educational advances in adult learning, understand bias, use deliberate practice, advance simulation, and then engage in the new educational opportunities provided by virtual reality and artificial intelligence? Maybe most importantly we hope to stimulate a new generation of educators who can contribute academically for their own career development and the improvement of surgical training in general. This issue hopes to fulfill a need concerning surgical education by changing the conversation and providing insight into current surgical training algorithms and evolving potentials for the future. We hope there is value in this issue beyond cardiothoracic surgery.

Edward D. Verrier, MD Division of Cardiothoracic Surgery Department of Surgery University of Washington 1959 NE Pacific Street

Box 356310

Seattle, WA 98919, USA

E-mail address: edver@uw.edu 